\title{
A new record of Pluteaceae (Agaricales) from Pakistan
}

\section{Khan $\mathrm{MB}^{1 *}$, Ishaq $\mathrm{M}^{1}$, Fiaz $\mathrm{M}^{1}$, Saba $\mathrm{M}^{2}$, Wenhua $\mathrm{L}^{3}$, Galappaththi $\mathrm{MCA}^{4}$ and Khalid $\mathrm{AN}^{5}$}

${ }^{1}$ Department of Botany, Hazara University Mansehra, Pakistan

${ }^{2}$ Department of Plant Sciences, Quaid-i-Azam University, Islamabad-45320, Pakistan

${ }^{3}$ Center for Mountain Futures, Kunming Institute of Botany, Chinese Academy of Science, Kunming, P.R. China

${ }^{4}$ Postgraduate Institute of Science, University of Peradeniya, Peradeniya, Sri Lanka

${ }^{5}$ University of the Punjab, Institut of Botany, Quaid-i-Azam Campus-54590, Lahore, Pakistan

Khan MB, Ishaq M, Fiaz M, Saba M, Wenhua L, Galappaththi MCA, Khalid AN 2021 A new record of Pluteaceae (Agaricales) from Pakistan. Studies in Fungi 6(1), 514-518, Doi 10.5943/sif/6/1/41

\begin{abstract}
During a survey of agarics from the Himalayan moist temperate regions in Pakistan, a new record Volvariella taylorii was collected. Full description, color images of basidiocarps, drawings of microscopic features, and a phylogenetic tree to show the placement of the taxon are provided.
\end{abstract}

Keywords - phylogeny - pink gills - taxonomy - volva - Volvariella taylorii

\section{Introduction}

Pluteaceae is a family of small to medium-sized macrofungi with free Lamellae and pink spores. Pluteaceae comprise the widely distributed Volvariella and Pluteus, rare Chamaeot, and Volvopluteus (Kirk et al. 2008). Most of the Volvariella species possess morphological characteristics such as a volva at the bottom of the stipe, lack of annulus, pink gills, free lamellae, spore print pinkish or brownish, pink spores thin-walled to somewhat thick-walled and growing on porous soils or dead wood. Volvariella species are best known as valuable foods (Prasad \& Singh 2020). Many of them grow naturally (Le \& Chu 2018). From Pakistan, five species of Volvariella are reported (Ahmad et al. 1997). The study aimed to provide data for the knowledge of the macrofungi with particular reference to the Himalayan regions of Pakistan.

\section{Materials \& methods}

\section{Collection and morphological analysis}

Basidiocarps of Volvariella taylorii were carefully dug out with the help of a knife and photographed in natural light. The forest and habitat types of the area and collection date were noted at the time of collation. The collected specimen was preserved by drying on a gas heater at $40-50^{\circ} \mathrm{C}$ until the moisture content was $<15 \%$ and kept in labelled boxes with necessary information for further analyses. A slide of gilled was prepared with $5 \% \mathrm{KOH}$ and congo red, and spore ornamentation was observed under 1000× magnification (MX4300H Techno Co., Ltd., Japan). Spore sizes were determined by measuring the length and width of at least 20 mature spores. The abbreviation "Q" is the range of "L/W" ratio of all the measured basidiospores, "Qe" is 
the average "L/W" ratio of the all measured basidiospores. Shape of the basidiospores is quoted according to Bas (1969).

\section{DNA extraction, PCR amplification, and sequencing}

A small piece of the specimen was grounded and placed 2\% CTAB buffer and DNA was extracted following the method of Porebski et al. (1997). ITS region of rDNA was amplified using a universal primer pair ITS-4 and ITS-1 (White et al. 1990). PCR was performed in $25-\mu \mathrm{L}$ reaction volume following the protocol of Gardes \& Bruns (1993). The PCR products were directly sequenced in Macrogen, Korea.

\section{Molecular characterization}

Both forward and reverse primer reads were manually edited and assembled to generate a consensus sequence in BioEdit 7.2.5 (Hall 1999). Homology searches were carried out at NCBI webpage using the BLAST tool, and sequences with closest identity were downloaded. Closest relatives of the species and other sequences representing the Volvariella were selected following recently published papers. All ambiguous portions with missing data and gaps were omitted from the final matrix. Online MUSCLE tool by EMBL-EBI, (http://www.ebi.ac.uk/Tools/msa/muscle/) was used for multiple sequences alignment (Edgar 2004). The maximum likelihood tree was generated using software MEGA 6.06 with ML method based on Tamura 3-parameter model with 1,000 rapid bootstrapping. Amylocorticium subincarnatum (AY586628) was selected as the out group.

\section{Results}

\section{Phylogenetic analyses}

The consensus sequence of local collection consisted of 760 nucleotides characters, showed 99\% and 100\% similarity with V. taylorii (HM246491) from Italy. In the same clade, the MK412340 V. taylorii from Germany are support with a strong bootstrap value. The consensus sequence of the ITS region of Pakistani collection consisted of 980 nucleotides characters. $V$. Taylorii showed 99\% similarity with Pluteus atromarginatus (EF530926) reported from Canada. An independent phylogenetic tree was constructed. in the ITS phylogram (Fig. 3). Bootstrap values $\geq 50 \%$ was cited on tree as significant. Pakistani species formed a well-supported clade with previously generated sequences. The Phylogenetic tree consists of 34 datasets of nucleotide sequences from different. The final aligned sequences contained 143/1302 conserve sites, 581/1302 variables sites, 386/1302 informative sites and 184/1302 singletons.

\section{Taxonomic description}

Volvariella taylorii (Berk. \& Broome) Singer 22: 401 (1951)

Figs 1, 2

\section{Description}

Pileus 2-2.5 cm broad, convex, hairy surface, light brown (7.5YR 5/4) color, incurved margin. Lamellae pinkish (6R 6/14), free, closed, narrow, unequal, even entire edges. Stipe 3-4cm long, white, thickened downward, glabrous, smooth and soft. Context white, smooth and soft. Basidiospores (1) 4.1-5.9 (6) $\times(0.7)$ 2.9-3.9 (4.6) $\mu \mathrm{m}, \mathrm{Q}=(1.3) 1.4-1.8$ (1.9); $\mathrm{Me}=4.6 \times 3.2 \mu \mathrm{m}$; $\mathrm{Qe}=1.5 \mu \mathrm{m}$, ellipsoid, thick-wall, hyaline in 5\% KOH. Basidia (2.7) 3.8-18.5 (20.6) $\times(1.2) 1.22-$ $6.3(6.4) \mu \mathrm{m}, \mathrm{Q}=$ (1.3) 1.5-3.2 (3.9); $\mathrm{Me}=10.2 \times 4.2 \mu \mathrm{m}$; $\mathrm{Qe}=2.4$, narrowly clavate to clavate, 2-4 spored, hyaline and thin-walled. Pleurocystidia $25.6-28.5 \times 10.2-12.6 \mu \mathrm{m}$, broadly fusiform, thin-walled, hyaline. Cheilocystidia 36-52 $\times 12-18 \mu \mathrm{m}$, fusoid-ventricose, clavate to narrow clavate, thin-walled. Pileipellis $5 \times 3.3 \mu \mathrm{m}$ wide, cylindric hyphae and thin-walled. Stipetipellis cutis regularly unbranched with septate hyphae and clamp connection was not observed. 


\section{Material examined}

Pakistan, Khyber Pakhtunkhwa, District Battagram 3750 m.a.s.l., in moist temperate forests dominated with Quercus incana Roxb. July 18, 2017 Muhammad Binyamin Khan (HUP-10388).

\section{Distribution}

Volvariella taylorii is widely distributed in temperate regions of Europe (Lange 1936, Kuhner \& Romagnesi 1953, Orton 1974), and North America (Shaffer 1957). This species was reported from Argentina by Singer (1953) and Shaffer (1957), Caribbean by Pegler (1983) and Nepal by Aryal et al. (2014).

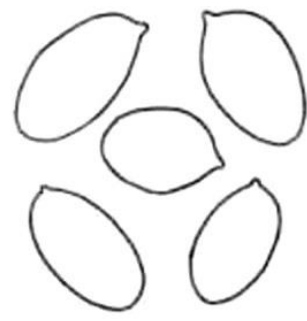

A

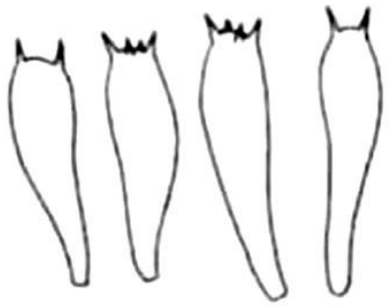

B
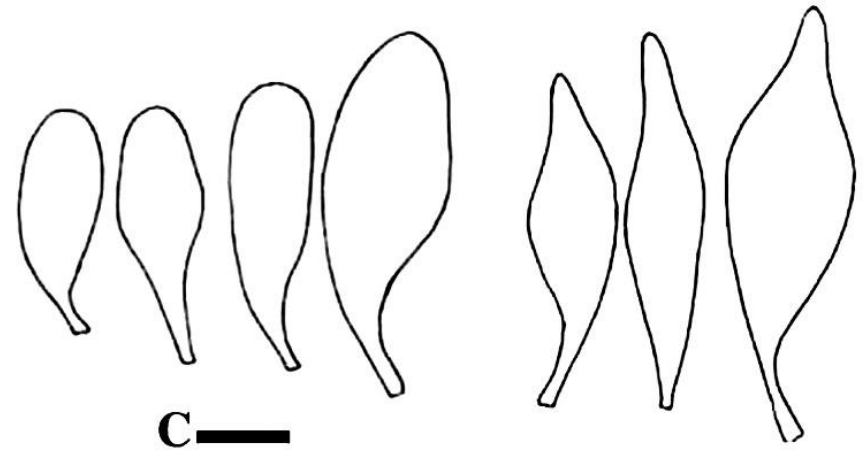

D

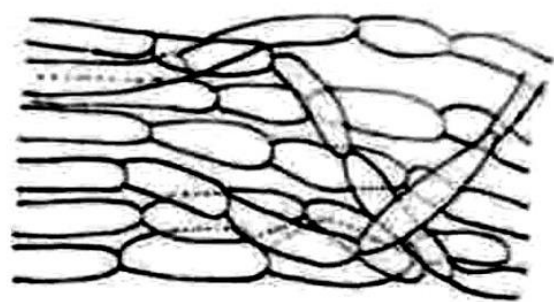

$\mathbf{E}$
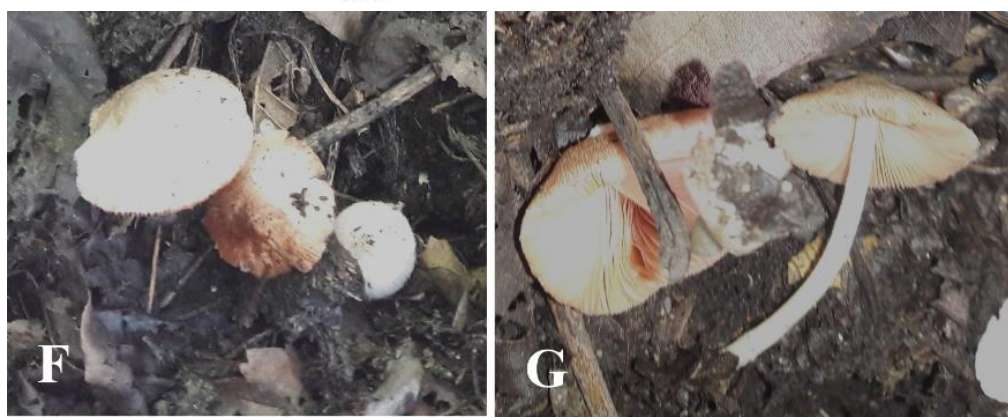

Fig. 1 - Morpho-anatomical features of Volvariella taylorii. A Basidiospore. B Basidia. C Cheilocystdia. D Pleurocystdia. E Stipetpellis. F, G Basidiocarps in the field. Scale bears: A = 1 $\mathrm{cm}, \mathrm{B}=6 \mu \mathrm{m}, \mathrm{C}=3 \mu \mathrm{m}, \mathrm{D}=8 \mu \mathrm{m}, \mathrm{E}=6 \mu \mathrm{m}, \mathrm{F}=7 \mu \mathrm{m}$. 


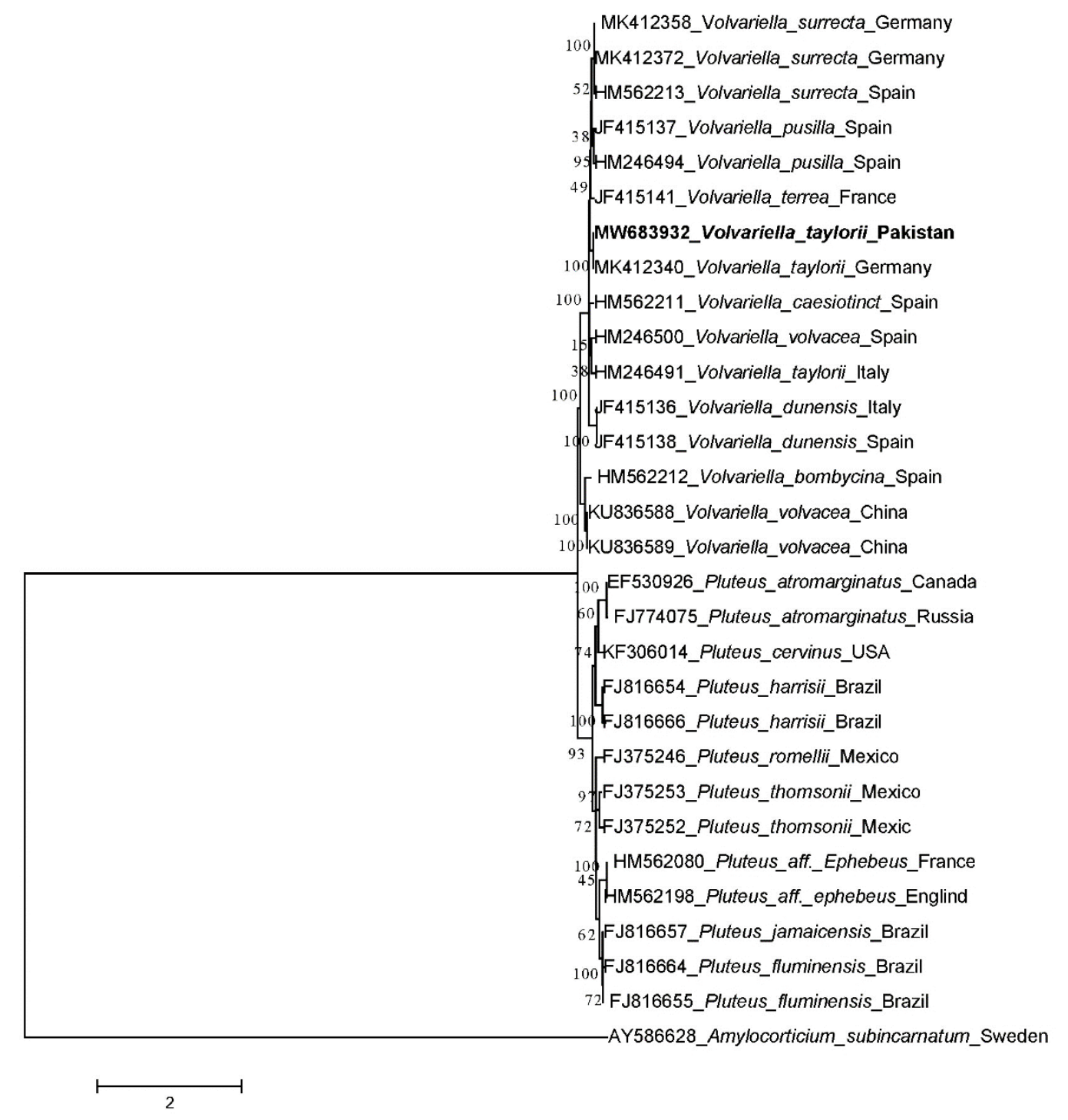

Fig. 2 - ITS-based phylogenetic analysis of Volvariella taylorii inferred by using Maximum Likelihood method in Tamura 3 parameter model. The sequences generated from Pakistani sequence are marked with bold black color.

\section{Discussion}

Macroscopic and microscopic details of the examined specimens match the description of Volvariella taylorii (Berk. \& Broome) Singer (1949), except for pileus coloration patterns. The Pakistani specimen has light brown pileus with hairy surface incurved towards the margin, while the type specimen is described with brownish-gray to light gray pileus, and center dark brown with abundant radial fibrils with entire margin (Niveiro et al. 2017). The stipe of Pakistani specimen thickened downward and glabrous matches the type description. The basidiospore and basidial shapes are similar in the Pakistani, type specimen and other specimens from different regions, but the basidia and spore sizes are smaller in our specimen compared with the Italy specimens. This Pakistani taxon represents a new record to Himalayan moist temperate regions of Pakistan.

\section{References}

Ahmad S, Iqbal SH, Khalid AN. 1997 - Fungi of Pakistan.Sultan Ahmad Mycological Society of Pakistan. Department of Botany, University of the Punjab, Lahore, Pakistan. 
Aryal HP, Poudel R, Budathoki U. 2014 - Macrofungi from Siddababa Sacred Grove: West, Nepal. Journal of Agriculture and Environment 15, 107-116.

Bas C. 1969 - Morphology and subdivision of Amanita and a monograph of its section Lepidella. Persoonia 5: 285-579.

Edgar RC. 2004. MUSCLE: Multiple sequence alignment with high accuracy and high throughput. Nucleic Acids Research 32: 1792-1797. Doi 10.1093/nar/gkh340

Gardes M, Bruns TD. 1993 - ITS primers with enhanced specificity for basidiomycetes application to the identification of mycorrhizae rusts. Molecular ecology 2(2), 113-118.

Hall TA. 2005 - Bioedit Version 7.0.4. Department of Microbiology, North Carolina State University.

Kirk PM, Cannon PF, Minter DW, Stalpers JA. 2008 - Dictionary of the Fungi Wallingford. UK: CABI, pp. 335.

Kuhner R, Romagnesi H. 1953 - Flore analytique des champignons supérieurs. Masson et Cie, Paris. pp. 1-252.

Lange J. 1936 - Flora agaricinaDanica. Recato A/S, Copenhagen. pp. 1-105.

Le HT, Chu NT. 2018 - New records of genus Volvariella (Pluteaceae) from Cuc Phuong National Park.Vietnam Journal of Science, Technology and Engineering 60(3), 81-88.

Niveiro N, Ramirez NA, Popoff OF, Albertó EO. 2017 - Volvariella (Pluteacae, Basidiomycota) en el Norte de la Argentina. Rodriguésia 68(4), 1459-1469.

Orton PD. 1974 - The European species of Volvariella Spegazzini. Bull. Mens. Soc. Linn. Lyon 43, 311-321.

Pegler D. 1983 - Agaric flora of the Lesser Antilles. Kew Bulletin, Additional series 9, 1-668.

Porebski S, Bailey LG, Baum BR. 1997 - Modification of a CTAB DNA extraction protocol for plants containing high polysaccharide and polyphenol components. Plant Mol. Biol. Rep, 15(1): $8-15$.

Prasad D, Singh VK. 2020 - National Web Conference.

Shaffer R. 1957 - Volvariella in North America. Mycologia 49, 545-579.

Singer R. 1953 - Quelques Agarics nouveaux de l'Argentine. Revue de mycologie 18, 3-23.

Singer, R. 1949. Mycoflora Australis. Beiheft zur Nova Hedwigia 29: 1-405.

White TJ, Bruns T, Lee SJWT, Taylor J. 1990 - Amplification and direct sequencing of fungal ribosomal RNA genes for phylogenetics. PCR protocols: a guide to methods and applications $18(1), 315-322$. 